\title{
MEMBUMIKAN NILAI PANCASILA PADA GENERASI BANGSA
}

\author{
Muhammad Awin Alaby \\ Sekolah Tinggi Keguruan dan Ilmu Pendidikan Kusumanegara, Jl. Raya Bogor Km.24 Cijantung, Jakarta \\ Timur, 13770, Indonesia, alaby@ stkipkusumanegara.ac.id
}

Diterima 29 Juni 2019, disetujui 25 September 2019, diterbitkan 31 Oktober 2019

Pengutipan: Alaby, A.M.(2019). Membumikan Nilai Pancasila pada Generasi Bangsa. Gema Wiralodra, Vol 10, No 2, Hal 179-189-61, Oktober 2019

\begin{abstract}
Pancasila as the state ideology becomes the basic reference for all Indonesian citizens in various sectors of life. But the fact is that nowadays the values of Pancasila are increasingly eroded due to the rapid influence of the progress of science, technology and arts that are not well-filtered. such as increasing crime, corruption, collusion and nepotism, radicalism, sexual crime, consumptive life, unproductive political life, and so on. To restore the value of Pancasila in social life, nation and state need actualization efforts. Through the actualization of the Pancasila values socialization is expected to become more down to earth in Indonesian society by involving all parties to actively participate in grounding Pancasila values to all aspects of life, in the three domains of informal, formal and non-formal education in order to form good character in the nation's generation, so Pancasila acceptability and credibility can be maintained in increasing the awareness and responsibility of the nation's generation towards a quality, intelligent, and future character.
\end{abstract}

Keywords: Pancasila value; Nation generation

\begin{abstract}
ABSTRAK
Pancasila sebagai ideologi negara menjadi acuan dasar bagi semua warga negara Indonesia diberbagai sektor kehidupan. Namun faktanya saat ini nilai-nilai luhur pancasila semakin terkikis akibat pengaruh pesatnya kemajuan ilmu pengetahuan, teknologi dan seni yang kurang terfilter dengan baik, Indikasi memudarnya praktik nilai-nilai pancasila dapat dilihat dari meningkatnya jumlah kasus yang melibatkan generasi bangsa yang mencerminkan lemahnya karakter bangsa, seperti meningkatnya kriminalitas, korupsi, kolusi dan nepotisme, radikalisme, kejahatan seksual, kehidupan yang konsumtif, kehidupan politik yang tidak produktif, dan sebagainya. Untuk mengembalikan nilai pancasila dalam kehidupan bermasyarakat, berbangsa dan bernegara perlu upaya aktualisasi. Melalui aktualisasi sosialisasi nilai-nilai pancasila diharapkan menjadi lebih membumi dimasyarakat Indonesia dengan melibatkan semua pihak untuk aktif berpartisipasi membumikan nilai-nilai pancasila ke semua aspek kehidupan, di tiga ranah pendidikan informal, formal dan non formal guna membentuk karakter yang baik pada generasi bangsa, sehingga akseptabilitas dan kredibilitas pancasila dapat terjaga dalam meningkatkan kesadaran dan tanggung jawab generasi bangsa terhadap masa depan yang berkualitas, cerdas, dan berkarakter.
\end{abstract}

Keywords: Pancasila value; Nation generation 


\section{PENDAHULUAN}

Generasi bangsa merupakan generasi penerus pemegang estafet kepemimpinan. Bangsa Indonesia harus menjaga dan mempraktikkan nilai-nilai pancasila bagi kehidupan masyarakat (Asmaroini, 2017). Negara di masa depan harus terus mempertahankan karakter bangsa. Era revolusi industri 4.0 memungkinkan kemajuan ilmu pengetahuan, teknologi dan seni begitu cepat mempengaruhi kehidupan bangsa Indonesia. Kemajuan ini menuntut generasi bangsa untuk dapat menyesuaikan akan perkembangannya. Keinginan kita untuk selalu maju agaknya banyak berdampak dan membawa pengaruh bagi bangsa ini, baik itu berupa dampak positif maupun negatif.

Di era ini diikuti dengan adanya trend yang semakin dinamis dan selalu diwarnai oleh ketidakteraturan dan ketidakpastian. Kondisi ini menimbulkan kecenderungan permasalahan baru yang semakin beragam dan multi dimensional Agung, I. (2010).. Teknologi informasi yang begitu cepat, telah membawa dampak bagi kehidupan manusia, yang dapat berdampak menguntungkan dan merugikan, berdampak menguntungkan apabila mampu memanfaatkannya untuk meningkatkan taraf hidup. Namun juga dapat berdampak merugikan, apabila terperdaya dengan pemanfaatan untuk kepentingan yang negatif. Hal ini dapat diartikan dampak ilmu pengetahuan dan teknologi berimplikasi langsung pada perubahan berbagai aspek kehidupan, termasuk terhadap karakter generasi bangsa.

Kemajuan teknologi memungkinkan terjadinya otomatisasi hampir di semua aspek kehidupan Ngafifi, M. (2014). Pendekatan baru dan teknologi yang menggabungkan antara dunia fisik, digital dan biologi secara fundamental akan mengubah pola hidup dan interaksi manusia (Tjandrawinata, 2016). Oleh sebab itu, di era 4.0 ini memudahkan manusia dalam menjalankan kehidupannya. Namun berbagai dekadensi moral seperti kriminalitas, semakin banyaknya korupsi, kolusi dan nepotisme, radikalisme, kejahatan seksual, kehidupan yang konsumtif, kehidupan politik yang tidak produktif, dan lain-lain yang seringkali menjadi wacana hangat dan tiada hentinya untuk dibicarakan hingga saat ini fenomena tersebut seakan-akan merupakan hal yang biasa dan akrab di dengar oleh masyarakat kita. 
Dekadensi moral terjadi hampir disemua tingkatan pendidikan di Indonesia baik dari tingkat pendidikan dasar hingga pada tingkat pendidikan tinggi (Cahyo, 2017). Hal ini tentu patut menjadi pekerjaan rumah untuk kita semua. Walau berbagai upaya yang ingin dibangun dan diimplementasikan oleh pemerintah untuk mendidik generasi bangsa ini melalui pendidikan karakter atau yang sejenisnya telah dilakukan, akan tetapi jika efektifitasnya tidak diperhatikan dalam mengemban amanah untuk mendidik putra-putri bangsa secara komprehensif dan humanis maka tujuan untuk menjadikan para peserta didik yang tidak hanya cakap secara intelektual tetapi anggun dalam moral pun sulit untuk di capainya.

Jika melihat secara kuantitas orang-orang Indonesia sudah banyak mengenyam dunia pendidikan, baik itu yang sudah tamat pendidikan dasar, menengah, ataupun tinggi. Namun anehnya segala problematika moral yang terjadi diindonesia tidak bisa lepas dari tingkah laku orang yang sudah pernah duduk dibangku sekolah dasar, menengah maupun tinggi, dan lebih meprihatinkan lagi jika di dalam dunia pendidikan terciderai oleh para akademisi itu sendiri.

Fenomena dekadensi moral dapat terjadi karena suatu bangsa kehilangan jati dirinya, dimana mereka tidak dapat mempertahankan apa yang menjadi identitasnya selama ini (Tulus, 2013). Mereka terlalu terlena dan kurang dapat memfilter budaya yang masuk ke Indonesia. Pada hakekat sesungguhnya, bangsa ini memiliki pancasila, pancasila merupakan karakter bangsa yang kini dikalangan generasi muda semangatnya mulai memudar akan kesadaran untuk menghayatinya. Mulai dari sila pertama hingga ke lima, semuanya mencakup berbagai lini kehidupan yang dijalani manusia, oleh sebab itu, sudah semestinya kita perlu meneguhkan kembali jati diri bangsa ini, melalui pancasila.

Mengingat sukses atau tidaknya suatu bangsa salah satu faktor utama adalah pada pendidikannya. Seberapa besar peran utama dunia pendidikan dalam mencetak sumber daya manusia yang berkarakter akan ikut menjadi determinan dalam memajukan suatu bangsa (Fahrudi, Zulki, \& Wiratmoko, 2016). Pada tahapan inilah peran strategis dunia pendidikan sangat diperlukan, tentunya dengan cara mengaktualisasi implementasi dari

Diterbitkan oleh: 
nilai pancasila dalam berbagai aspek tingkatan pendidikan yang ada, agar lebih maksimal dalam menjalankan fungsi pendidikan dan pengajarannya (Yudistira, 2016).

\section{TINJAUAN PUSTAKA}

Istilah ideologi berasal dari kata idea, yang artinya gagasan, konsep, pengertian dasar, cita-cita; dan logos yang berarti ilmu. Ideologi secara etimologis, artinya ilmu tentang ide-ide (the science of ideas), atau ajaran tentang pengertian dasar (Kaelan, 2013: 60-61). Dalam Kamus Besar Bahasa Indonesia, ideologi didefinisikan sebagai kumpulan konsep bersistem yang dijadikan asas pendapat yang memberikan arah dan tujuan untuk kelangsungan hidup. Ideologi juga diartikan sebagai cara berpikir seseorang atau suatu golongan. Ideologi dapat diartikan paham, teori, dan tujuan yang merupakan satu program sosial politik (Kamus Besar Bahasa Indonesia, 2008: 517).

Pancasila adalah dasar negara, ideologi bangsa dan falsafah serta pandangan hidup bangsa, yang di dalamnya terkandung nilai dasar, nilai instrumental dan nilai praksis. Selain itu Pancasila sebagai ideologi terbuka setidaknya memiliki dua dimensi nilai- nilai, yaitu nilai-nilai ideal dan aktual. Namun nilai-nilai itu kondisinya dipengaruhi oleh nilainilai yang dibawa globalisasi, sehingga berdampak terjadinya pergeseran peradaban, yang juga membawa perubahan pemaknaan dan positioning Pancasila (Sultan Hamengku Buwono X, Kongres Pancasila IV, UGM 2012).

Abdulgani (1979) menyatakan bahwa Pancasila adalah leitmotive dan leitstar, dorongan pokok dan bintang penunjuk jalan. Tanpa adanya leitmotive dan leitstar Pancasila ini, kekuasaan negara akan menyeleweng. Oleh karena itu, segala bentuk penyelewengan itu harus dicegah dengan cara mendahulukan Pancasila dasar filsafat dan dasar moral (Abdulgani, 1979:14). Agar Pancasila menjadi dorongan pokok dan bintang penunjuk jalan bagi generasi penerus pemegang estafet kepemimpinan nasional, maka nilai-nilai Pancasila harus dibumikan kepada para generasi bangsa melalui aktualisasi nilai Pancasila.

Pentingnya Pancasila sebagai ideologi negara bagi generasi bangsa adalah untuk memperlihatkan peran ideologi sebagai penuntun moral dalam kehidupan bermasyarakat,

Diterbitkan oleh: 
berbangsa, dan bernegara sehingga ancaman berupa penyalahgunaan narkoba, radikalisme, terorisme, kejahatan seksual, kolusi dan korupsi dapat dicegah. Hasil Survei yang dilakukan KOMPAS yang dirilis pada 1 Juni 2008 menunjukkan bahwa pengetahuan masyarakat tentang Pancasila merosot secara tajam, yaitu 48,4\% responden berusia 17 sampai 29 tahun tidak mampu menyebutkan silai-sila Pancasila secara benar dan lengkap. 42,7\% salah menyebut sila-sila Pancasila, lebih parah lagi, 60\% responden berusia 46 tahun ke atas salah menyebutkan sila-sila Pancasila. Fenomena tersebut sangat memprihatinkan karena menunjukkan bahwa pengetahuan tentang Pancasila yang ada dalam masyarakat tidak sebanding dengan semangat penerimaan masyarakat terhadap Pancasila (Ali, 2009: 2).

Sering kali kita menyaksikan di berbagai media massa yang memberitakan elemen masyarakat tertentu memaksakan kehendaknya dengan cara kekerasan kepada elemen masyarakat lainnya. Berdasarkan laporan hasil survei Badan Pusat Statistik di 181 Kabupaten/Kota, 34 Provinsi dengan melibatkan 12.056 responden sebanyak 89,4 \% menyatakan penyebab permasalahan dan konflik sosial yang terjadi tersebut dikarenakan kurangnya pemahaman dan pengamalan nilai-nilai Pancasila (Dailami, 2014:3).

Berdasarkan data yang dirilis Kepolisian Republik Indonesia (POLRI) tahun 2013, POLRI mengklaim telah menangani 32.470 kasus narkoba, baik narkoba yang berjenis narkotika, narkoba berjenis psikotropika maupun narkoba jenis bahan berbahaya lainnya. Angka ini meningkat sebanyak 5.909 kasus dari tahun sebelumnya. Pasalnya, pada tahun 2012 lalu, kasus narkoba yang ditangani oleh POLRI hanya sebanyak 26.561 kasus narkoba (http://nasional.sindonews.com) .

Hal tersebut jelas mengancam generasi bangsa, dekadensi moral yang terus melanda bangsa Indonesia yang ditandai dengan mulai mengendurnya ketaatan masyarakat terhadap norma-norma sosial yang hidup dimasyarakat Iskarim, M. (2017). Hal itu, menunjukkan pentingnya membumikan nilai-nilai pancasila melalui tiga ranah lingkungan pendidikan keluarga (informal), sekolah (formal) dan masyarakat (non formal) Alawiyah, F. (2012. Begitupun dalam kehidupan politik, para elit politik (eksekutif dan legislatif) mulai

Diterbitkan oleh: 
meninggalkan dan mengabaikan budaya politik yang santun, kurang menghormati fatsoen politik dan kering dari jiwa kenegarawanan Widodo, W. (2014)..

Menurut Alfred North Whitehead (1864-1947), tokoh filsafat proses, berpandangan bahwa semua realitas dalam alam mengalami proses atau perubahan, yaitu kemajuan, kreatif dan baru. Realitas itu dinamik dan suatu proses yang terus menerus menjadi, walaupun unsur permanensi realitas dan identitas diri dalam perubahan tidak boleh diabaikan. Sifat alamiah itu dapat pula dikenakan pada ideologi Pancasila sebagai suatu realitas. Yang jadi permasalahannya, bagaimana nilai-nilai Pancasila itu diaktualisasikan dalam praktik kehidupan berbangsa dan bernegara?

\section{PEMBAHASAN}

Aktualisasi nilai pancasila perlu disosialisasikan, diinternalisasikan dan diperkuat implementasinya, dalam praktik kehidupan berbangsa dan bernegara dengan memperkuat karakter generasi bangsa dalam berperan serta membangun pemahaman masyarakat akan kesadaran nasional

Aktualisasi nilai dalam praktek kehidupan berbangsa dan bernegara mengarahkan adanya 3 nilai yang terkandung dalam ideologi Pancasila. Tiga nilai itu adalah:

1. Nilai dasar, yaitu suatu nilai yang bersifat sangat abstrak dan permanen, yang terlepas dari pengaruh perubahan waktu. Nilai dasar merupakan prinsip, yang bersifat sangat abstrak, bersifat sangat umum, tidak terikat oleh waktu dan tempat, dengan kandungan kebenaran yang bagaikan aksioma. Dari aspek kandungan nilainya, maka nilai dasar berkenaan dengan eksistensi sesuatu, yang mencakup cita-cita, tujuan, tatanan dasar dan ciri khasnya. Nilai dasar Pancasila ditetapkan oleh para the founding fathers. Nilai dasar Pancasila tumbuh baik dari sejarah perjuangan bangsa Indonesia melawan penjajahan yang telah menyengsarakan rakyat, maupun dari cita-cita yang ditanamkan dalam agama dan tradisi tentang suatu masyarakat yang adil dan makmur berdasarkan kebersamaan, persatuan dan kesatuan seluruh warga masyarakat.

2. Nilai instrumental, yaitu suatu nilai yang bersifat kontekstual. Nilai instrumental merupakan penjabaran dari nilai dasar tersebut, yang merupakan arahan kinerjanya

Diterbitkan oleh: 
untuk kurun waktu tertentu dan untuk kondisi tertentu. Nilai instrumental ini dapat dan bahkan harus disesuaikan dengan tuntutan zaman. Namun nilai instrumental haruslah mengacu pada nilai dasar yang dijabarkannya. Penjabaran itu bisa dilakukan secara kreatif dan dinamik dalam bentuk-bentuk baru untuk mewujudkan semangat yang sama, dalam batas-batas yang dimungkinkan oleh nilai dasar itu. Dari aspek kandungan nilainya, maka nilai instrumental merupakan kebijaksanaan, strategi, organisasi, sistem, rencana, program, bahkan juga proyek-proyek yang menindaklanjuti nilai dasar tersebut. Lembaga negara yang berwenang menyusun nilai instrumental ini adalah DPR, MPR, dan Presiden.

3. Nilai praksis, yaitu nilai yang terkandung dalam kenyataan sehari-hari, berupa cara bagaimana rakyat mengaktualisasikan nilai Pancasila. Nilai praksis terdapat pada demikian banyak wujud penerapan nilai-nilai Pancasila, baik secara tertulis maupun tidak tertulis, baik oleh cabang eksekutif, legislatif, maupun yudikatif, oleh ekonomi, oleh pimpinan kemasyarakatan, bahkan oleh warganegara secara perseorangan. Dari aspek kandungan nilainya, nilai praksis merupakan arena pergulatan antara idealisme dan realitas. Jika ditinjau dari segi pelaksanaan nilai yang dianut, maka sesungguhnya pada nilai praksislah ditentukan tegak atau tidaknya nilai dasar dan nilai instrumental itu. singkatnya bukan pada rumusan abstrak, dan bukan juga pada kebijaksanaan, strategi, rencana, program atau proyek itu sendiri terletak batu ujian terakhir dari nilai yang dianut, tetapi pada kualitas pelaksanaannya di lapangan. Bagi suatu ideologi, yang paling penting adalah bukti pengamalannya atau aktualisasinya dalam kehidupan bermasyarakat, berbangsa, dan bernegara. Suatu ideologi dapat mempunyai rumusan yang amat ideal dengan ulasan yang amat logis serta konsisten pada tahap nilai dasar dan nilai instrumentalnya. Akan tetapi, jika pada nilai praksisnya rumusan tersebut tidak dapat diaktualisasikan, maka ideologi tersebut akan kehilangan kredibilitasnya.

Ancaman terbesar bagi suatu ideologi adalah menjaga konsistensi antara nilai dasar, nilai instrumental, dan nilai praksisnya. Sudah barang tentu jika konsistensi ketiga nilai itu dapat ditegakkan, maka terhadap ideologi itu tidak akan ada masalah. Jika terdapat inkonsisitensi dalam tiga tataran nilai tersebut maka akan menjadi suatu masalah baru. 
Dalam memelihara konsistensi untuk mengaktualisasikan nilai Pancasila ke dalam praktik hidup berbangsa dan bernegara, maka perlu Pancasila yang bersifat formal, abstrak, umum universal yang ditransformasikan menjadi rumusan Pancasila yang kolektif nan umum, dan bahkan menjadi Pancasila yang khusus individual Artinya, Pancasila menjadi sifat-sifat dari subjek kelompok dan individual, sehingga menjiwai semua tingkah laku dalam lingkungan praksis nya dalam aspek kenegaraan,politik dan pribadi.

Aktualisasi nilai pancasila harus mulai disosialisasikan dari berbagai lingkungan pendidikan. Baik itu di keluarga sebagai pendidikan informal, sekolah sebagai lembaga pendidikan formal, maupun dalam masyarakat sebagai lembaga pendidikan non formal. Di semua lingkungan pendidikan tersebut harus dibumikan dengan nilai- nilai Pancasila, seperti halnya dibawah ini.

1. Dalam lingkungan lembaga pendidikan Informal seperti Keluarga. Tahap pendidikan yang pertama dan utama bagi anak ada di keluarga, Artinya bagaimana karakter anak berkembang kedepan bergantung dari pola asuh yang diterapkan di rumah. Apakah pola asuh permisif yang memberi kebebasan pada anak, pola asuh otoriter yang mewajibkan anak untuk selalu patuh, atau pola asuh autoritatif yang artinya antara orangtua dan anak saling mengerti tanggungjawab, hak dan kewajiban masing-masing. Selanjutnya untuk menanamkan moral yang baik pada anak, orang tua juga harus memiliki karakter yang tentu saja lebih baik terlebih dahulu, dengan begitu orangtua seakan menjadi teladan atau row model bagi anak dalam bertindak sehingga anak senantiasa berhati-hati dalam bertingkah laku.

2. Dalam lingkungan lembaga pendidikan Formal / Sekolah. Dalam membentuk karakter peserta didik peran tenaga pendidik sangat penting, Para tenaga pendidik yang merupakan orangtua kedua peserta didik di sekolah, perlu senantiasa mengimplementasikan nilai-nilai Pancasila yang sebenarnya. Mulai dari kebiasaan untuk berdoa setiap kegiatan belajar mengajar, saling toleransi antar teman, menumbuhkan sikap peduli sesama, dan tidak membeda- bedakan antara peserta didik satu dengan peserta didik yang lain.

Diterbitkan oleh: 
3. Dalam lingkungan lembaga pendidikan Informal/ Masyarakat. Mengimplementasikan nilai-nilai Pancasila di masyarakat tentu dimulai dari sekitar lingkungan rumah. Keberagaman etnis yang ada di masyarakat hendaknya menjadi suatu warna tersendiri bagi mereka, sebagaimana semboyan yang dimiliki bangsa Indonesia yaitu “ Bhinneka Tunggal Ika, walaupun negara Indonesia terdiri dari beragam suku, namun kerukunan antar seluruh umat di Indonesia tetap perlu dijunjung tinggi.

Dengan cara kembali melakukan aktualisasi nilai - nilai pancasila di berbagai aspek moral bangsa Indonesia sehingga dapat kembali menuju jati dirinya, nilai pancasila tersebut akan terimplementasi dalam ranah kognitif, afektif dan psikomotorik bangsa. Hal demikian sangat penting untuk diingat karena dapat menjadi parameter atau tolak ukur sampai seberapa jauh tingkat perubahan tingkah laku seseorang, dan untuk mengetahui tingkat ketercapaian dalam menempuh proses pendidikan. Sehingga pada akhirnya dapat benar-benar menghasilkan output yang cerdas, unggul, berdaya saing, bermoral dan berkarakter.

Perlu diketahui kesuksesan seseorang tidak ditentukan semata - mata oleh pengetahuan dan kemampuan teknis saja, tetapi lebih oleh pengetahuan mengelola diri dan orang lain, hal ini membuktikan bahwa kesuksesan seseoarang lebih ditentukan oleh kemampuan manage self daripada kemampuan knowledge.

Dengan demikian, sebagai karakter bangsa Indonesia aktualisasi nilai - nilai pancasila merupakan sebuah konsekuensi logis guna semakin terciptanya sumber daya manusia yang cerdas holistik sebagaimana tertera dalam tujuan pendidikan nasional dalam UU No 20 tahun 2003 tentang Sisdiknas, yakni bertujuan untuk berkembangnya potensi peserta didik agar menjadi manusia yang beriman dan bertaqwa kepada Tuhan yang maha Esa, berakhlak mulia, sehat, berilmu, cakap, kreaif, mandiri dan menjadi warga negara yang demokratis serta bertanggung jawab.

\section{KESIMPULAN}

Dari uraian tersebut di atas dapat disimpulkan bahwa membumikan nilai-nilai pancasila merupakan aspek yang penting untuk menangkal radikalisme dan membangun

Diterbitkan oleh: 
karakter generasi bangsa, dinamika dalam mengaktualisasikan nilai Pancasila ke dalam kehidupan bermasyarakat, berbangsa, dan benegara adalah suatu keniscayaan, agar Pancasila tetap selalu relevan pada fungsinya memberikan acuan dasar bagi pengambilan kebijaksanaan dan pemecahan masalah dalam kehidupan berbangsa dan bernegara supaya loyalitas warga masyarakat dan warganegara terhadap Pancasila tetap tinggi sehingga apatisme, resistensi terhadap pancasila bisa diminimalisir dan persatuan indonesia tetap terjaga. untuk mensukseskan itu perlu upaya sosialisasi dari berbagai lingkungan pendidikan, baik itu di keluarga sebagai pendidikan informal, sekolah sebagai lembaga pendidikan formal, maupun dalam masyarakat sebagai lembaga pendidikan non formal. Di semua lingkungan pendidikan tersebut harus dibumikan dengan nilai-nilai Pancasila serta perlunya upaya perubahan dan pembaharuan dalam mengaktualisasikan nilai Pancasila sehingga akseptabilitas dan kredibilitas pancasila dapat terjaga dalam meningkatkan kesadaran dan tanggung jawab terhadap masa depan generasi bangsa yang berkualitas, cerdas dan berkarakter.

\section{DAFTAR PUSTAKA}

Abdulgani, R. (1979). Pengembangan Pancasila Di Indonesia. Jakarta: Yayasan Idayu

Agung, I. (2010). Perspektif Multidimensional Pendidikan Pembangunan Berkelanjutan: Pemikiran Awal Konsep dan Penerapan. Jurnal Pendidikan dan Kebudayaan, Vol 16, No 4, 453-468

Alawiyah, F. (2012). Kebijakan dan Pengembangan Pembangunan Karakter melalui Pendidikan di Indonesia. Jurnal Aspirasi, Vol 3, No 1, 87-101

Ali, A. (2009). Negara Pancasila Jalan Kemaslahatan Berbangsa. Jakarta: Pustaka LP3ES.

Asmaroini, A. P. (2017). Menjaga Eksistensi Pancasila Dan Penerapanya Bagi Masyarakat di Era Globalisasi. JPK: Jurnal Pancasila dan Kewarganegaraan, Vol 1, No 2, 5064.

Budimansyah. (2010). Penguatan Pendidikan Kewarganegaraan Untuk Membangun Karakter Bangsa. Bandung: Widya Aksara Press.

Diterbitkan oleh:

Universitas Wiralodra

Jln. Ir. H. Juanda Km 3 Indramayu, Jawa Barat 
Cahyo, E. D. (2017). Pendidikan Karakter Guna Menanggulangi Dekadensi Moral Yang Terjadi Pada Siswa Sekolah Dasar. EDUHUMANIORA: Jurnal Pendidikan Dasar, Vol 9, No 1, 16-26.

Fahrudi, Erista Zulki, and Dheny Wiratmoko. (2016). "Peran pendidikan sebagai pondasi penumbuhan karakter bangsa Indonesia.

Hadi, H.P. (1994). Hakikat dan Muatan Filsafat Pancasila. Yogyakarta: Penerbit Kanisius.

Iskarim, M. (2017). Dekadensi Moral di Kalangan Pelajar (Revitalisasi Strategi PAI dalam Menumbuhkan Moralitas Generasi Bangsa). Edukasia Islamika, 1-20.

Kansil, C.S.T. (1986). Pancasila dan Undang-Undang Dasar 1945. Jakarta: Pradnya Paramita.

Koesoema. (2010). Pendidikan Karakter: Strategi Mendidik Anak di Zaman Global. Jakarta: Grasindo.

Kaelan. (2010). Pendidikan Pancasila. Yogyakarta: Paradigma

Kaelan. (2013). Negara kebangsaaan Pancasila, kultural, historis, Filosofis, Yuridis dan aktualisasinya. Yogyakarta: Paradigma

Zed, M. (2016). Metode Penelitian Kepustakaan. Jakarta: Pustaka obor Indonesia.

Ngafifi, M. (2014). Kemajuan teknologi dan pola hidup manusia dalam perspektif sosial budaya. Jurnal Pembangunan Pendidikan: Fondasi dan Aplikasi, 2(1).

Surono, E. (2010). Nasionalisme dan Pembangunan Karakter Bangsa. Yogyakarta: Pusat studi Pancasila press.

(http://nasional.sindonews.com/read/2013/12/27/13/821215/sepanjang2013-kasusnarkoba-meningkat).

Supadjar, D. (1990). Konsep Kefilsafatan tentang Tuhan Menurut Alfred Nort Whitehead. (Doctoral dissertation, Universitas Gajah Mada )

Tjandrawinata, R. R. (2016). Industri 4.0: Revolusi industri abad ini dan pengaruhnya pada bidang kesehatan dan bioteknologi. Jurnal Medicinus, Vol 29, No 1 .

Diterbitkan oleh: 
Tulus, M. (2013). Konfigurasi Pendidikan Karakter Berparadigma Kebangsaan; Usaha Meneguhkan Identitas Diri Bangsa dari Kungkungan Arus Globalisasi. el-hikmah, Vol 2, No 2.

Yudistira, Y. (2016). Aktualisasi \& Implementasi Nilai-Nilai Pancasila dalam Menumbuh Kembangkan Karakter Bangsa. In Seminar Nasional Hukum Universitas Negeri Semarang, Vol. 2, No. 1, pp. 421-436.

Widodo, W. (2014). Muwujudkan Budaya Politik Santun, Bersih dan Beretika dalam Rangka Memperkokoh Kehidupan Berbangsa dan Bernegara. HUMANIKA, Vol 19 No 1, 114-129. 